\title{
UPAYA PENINGKATAN PRODUKTIVITAS TENAGA KERJA KONTRAKTOR DI WILAYAH KABUPATEN PASER, KALIMANTAN TIMUR
}

\author{
Vera Victya ${ }^{1}$ dan Henry Wardhana ${ }^{2}$ \\ ${ }^{1}$ Program Studi Magister Teknik Sipil Universitas Lambung Mangkurat \\ ${ }^{2}$ Faculty of Engineering, Lambung Mangkurat University
}

\begin{abstract}
ABSTRAK
Produktivitas merupakan hal yang sangat penting bagi setiap tenaga kerja dalam penyelesaian suatu pekerjaan. Produktivitas kerja yang tinggi harus di miliki oleh setiap tenaga kerja di semua sektor konstruksi. Produktivitas tenaga kerja yang tinggi sangat di perlukan untuk keberhasilan proyek konstruksi. Tinggi rendahnya produktivitas kerja para tenaga kerja sangat mempengaruhi waktu pelaksanaan proyek konstruksi tersebut. Besarnya tingkat produktivitas tenaga kerja dipengaruhi oleh banyak faktor diantara adalah umur, pengalaman kerja/masa kerja, keahlian tenaga kerja, tingkat pendidikan, kesesuaian upah, kesehatan pekerja, kondisi lapangan/cuaca, komposisi kelompok kerja dan hubungan antar pekerja. Semua variabel itu mempunyai pengaruh yang besar terhadap produktivitas tenaga kerja pada pekerjaan pasangan dinding. Dari hasil penelitian ini didapatkan tingkat produktivitas pekerjaan pasangan dinding batako pada ketinggian O lantai sampai $50 \mathrm{~cm}$ sebesar 1,42 $\mathrm{m}^{2} / \mathrm{jam}$, pada ketinggian $50 \mathrm{~cm}$ sampai 2 meter sebesar $2,20 \mathrm{~m}^{2} / \mathrm{jam}$, pada ketinggian 2 meter sampai 3,5 meter sebesar 1,95 m²/jam, dan pada ketinggian 3,5 meter sampai 6 meter sebesar 1,70 $\mathrm{m}^{2} / \mathrm{jam}$. Upaya yang harus dilakukan dalam peningkatan produktivitas tenaga kerja adalah dengan lebih memperketat pengawasan terhadap tenaga kerjanya sehingga dapat bekerja secara maksimal serta perlunya pelatihan tenaga kerja untuk mendapatkan sertifikat keahlian sehingga yang dipilih oleh kontraktor adalah pekerja yang sudah memiliki seritifikat keahlian agar pada saat pekerja terjun ke lapangan sesuai dengan apa yang kita inginkan.
\end{abstract}

Kata Kunci: produktivitas, tenaga kerja, proyek konstruksi.

\section{PENDAHULUAN}

Produktivitas adalah sesuatu yang sangat penting bagi semua tenaga kerja dalam menyelesaikan suatu kegiatan pekerjaan. Produktivitas yang tinggi harus di miliki oleh semua tenaga kerja di sektor konstruksi sehingga dapat bersaing di bidangnya. Produktivitas pekerja yang tinggi di perlukan untuk kesuksesan proyek konstruksi. Produktivitas menjadi satu di antara penyebab rendahnya pekerjaan yang akan dihasilkan.

Menurut Dinas Tenaga Kerja Dan Transmigrasi Provinsi Kalimantan Timur, Masalah mengenai ketenagakerjaan di Provinsi ini diantaranya adalah sangat rendahnya tingkat produktivitas tenaga kerja, besarnya jumlah pengangguran terbuka dan setengah pengangguran, rendahnya tingkat pengetahuan, tingkat pendidikan, dan tingkat keterampilan pencari kerja serta rendahnya

Correspondence: Vera Victya

Email :veravictya@gmail.com perlindungan dan kesejahteraan pekerja (Disnakertrans Kaltim, 2016).

Indikator produktivitas tenaga kerja juga dapat di lihat dari lamanya penduduk untuk bekerja. Produktivitas di anggap membaik jika tenaga kerja bekerja semakin lama akan menghasilkan output yang lebih besar. Batasan jam kerja yang biasanya di pakai sebagai jumlah jam kerja normal selama satu minggu adalah 35 jam. Apabila jumlah jam kerja dalam seminggu kurang dari 35 jam di anggap pekerja mempunyai produktivitas rendah atau disebut juga setengah pengangguran. Berdasarkan hasil Sakernas tahun 2016, dari seluruh pekerja yang ada di Kabupaten Paser terdapat 40,29 persen pekerja yang bekerja dengan jam kerja dibawah 35 jam, dan sebanyak 59,71 persen pekerja yang bekerja dengan jam kerja diatas 35 jam. Ini berarti lebih dari sepertiga jumlah pekerja memiliki produktivitas rendah (BPS Kabupaten Paser, 2017) 


\section{UPAYA PENINGKATAN PRODUKTIVITAS TENAGA KERJA KONTRAKTOR DI WILAYAH KABUPATEN PASER, KALIMANTAN TIMUR \\ Vera Victya}

Produktivitas tenaga kerja yang rendah menyebabkan banyak kerugian seperti kerugian finansial, keterlambatan penyelesaian pekerjaan yang berakibat status proyek menjadi kritis. Rendahnya tingkat produktivitas tenaga kerja banyak ditemui di Kabupaten Paser, Kalimantan Timur. Pada saat ini Kabupaten Paser sedang gencar-gencarnya melaksanakan pembangunan sarana infrastruktur, satu diantara nya yaitu pembangunan perumahan. Di setiap lahan kosong dimanfaatkan untuk pembangunan perumahan dari bangunan yang sederhana sampai bangunan yang mewah. Apabila tidak didukungnya produktivitas yang memadai dari tenaga kerja para kontraktor pelaksana maka akan terjadi keterlambatan penyelesaian pekerjaan pada pelaksanaan proyek serta rendahnya kualitas dari hasil pekerjaan tersebut.

Pekerjaan yang sering mengalami keterlambatan biasanya merupakan item pekerjaan detail yang di kerjakan secara manual oleh para tenaga kerja tanpa bantuan alat-alat canggih yang bisa mempercepat pekerjaan tersebut, sebagai contoh yaitu pakerjaan galian tanah pondasi, pasangan dinding bata, pekerjaan pemasangan lantai keramik, pekerjaan pemasangan atap dan finishing. Menurut Sumber Kantor Dinas Cipta Karya Kabupaten Paser, karena kelalaian dari pihak kontraktor pelaksanaan proyek khususnya pada kegiatan pembangunan banyak terdapat paket pekerjaan yang mengalami keterlambatan penyelesaian pekerjaan.

Dari beberapa pembangunan perumahan yang ada Di Wilayah Kabupaten Paser, Pembangunan Perumahan Tapis Indah Regency jumlah rumah yang di bangun lebih banyak dibandingkan dengan perumahan yang lainnya. Sehingga Penelitian ini akan dilaksanakan pada proyek pembangunan Perumahan Tapis Indah Regency Di Wilayah Kabupaten Paser, Kalimantan Timur yang difokuskan pada pekerjaan pasangan batako. didapatkan dengan cara pengamatan langsung dilapangan untuk mendapatkan data produktivitas pekerjaan pasangan batako, penyebaran kuisioner kepada para tukang batu yang bekerja serta melakukan wawancara kepada pihak yang bersangkutan.

Obyek yang akan diteliti sebagai sumber data dalam penelitian ini adalah tukang batu yang bekerja pada pekerjaan pasangan dinding menggunakan batako, yaitu mengenai faktor-faktor yang mempengaruhi kinerja tenaga kerjanya khususnya mengenai variabel kondisi lapangan, usia, pengalaman kerja/masa kerja, keahlian tenaga kerja, tingkat pendidikan, kesesuaian upah tenaga kerja, kesehatan tenaga kerja, hubungan antar tenaga kerja dan Tim kelompok kerja.

Pelaksanaan penelitian dilakukan pada Proyek Pembangunan Perumahan Tapis Indah Regency Di Wilayah Kabupaten Paser, Kalimantan Timur. Pengamatan dilakukan selama jam kerja yaitu dari pukul 08.00 sampai dengan pukul 18.00, dengan waktu istirahat selama satu jam yaitu pada pukul 12.00 sampai dengan pukul 13.00. Sampel penelitian berupa kuisioner yang akan disebarkan kepada para tukang batu yang bekerja pada pekerjaan pasangan batako dan jumlah sampel yang diteliti yaitu sebanyak 30 orang pada Proyek Pembangunan Perumahan Tapis Indah Regency Di Wilayah Kabupaten Paser, Kalimantan Timur.

Penelitian ini dilakukan melalui lima tahapan yaitu tahap persiapan, tahap survey lapangan dan pengumpulan data, tahap penelitian dan rekapitulasi data, tahap analisis data dan yang terakhir tahap pembahasan hasil analisis untuk mendapatkan kesimpulan serta saran.

Gambaran skema kerangka pikir untuk penelitian upaya peningkatan produktivitas tenaga kerja kontraktor, seperti pada Gambar 1.

\section{METODE PENELITIAN}

Penelitian ini dilakukan dengan cara melakukan pengamatan langsung ke lokasi penelitian. Data-data primer yang diperlukan 


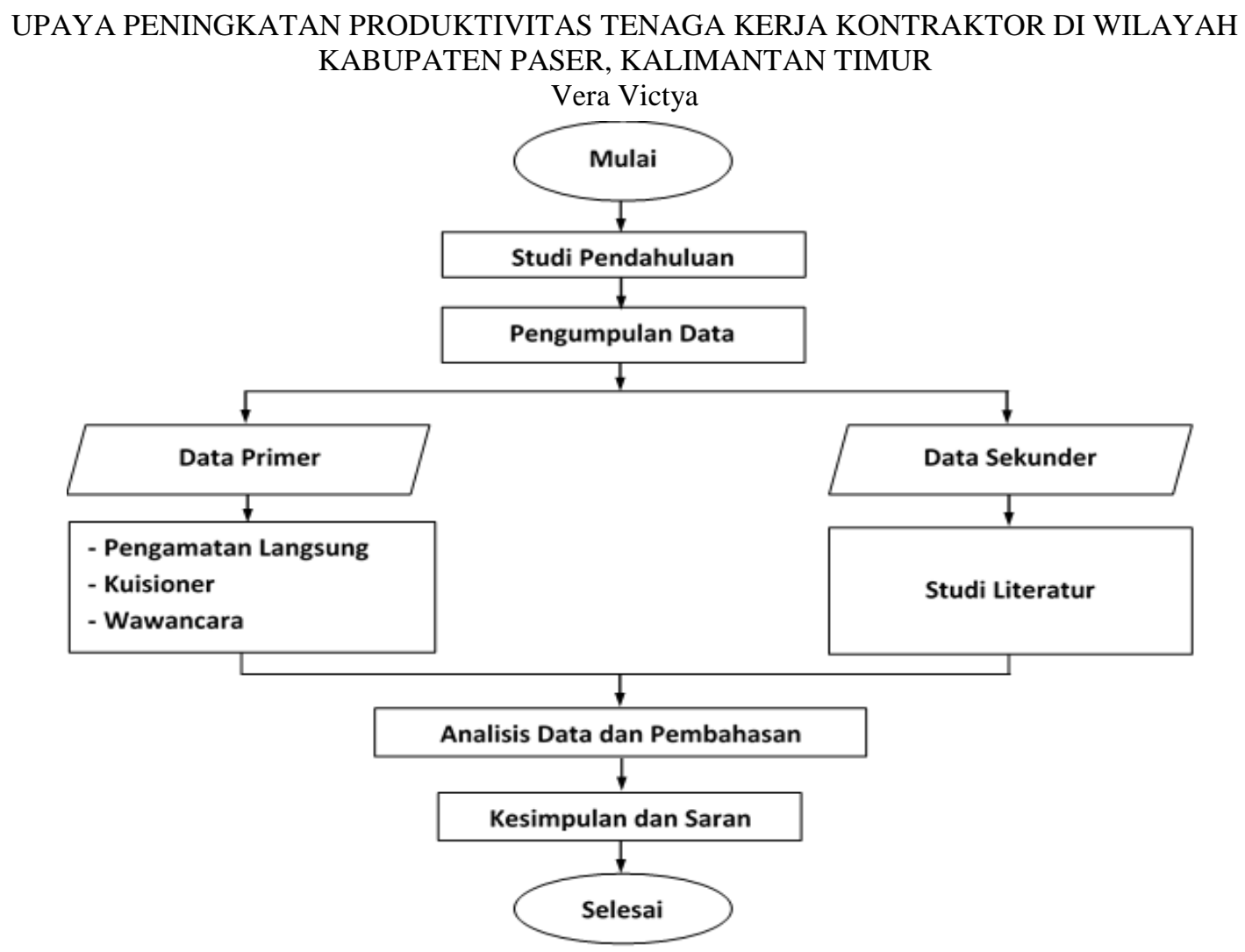

Gambar 1. Bagan Alir Penelitian

Variabel dalam penelitian ini yang dapat mempengaruhi produktivitas tenaga kerja yaitu:

1. Usia

2. Keahlian Tenaga Kerja

3. Pengalaman Tenaga Kerja

4. Tingkat Pendidikan

5. Kesesuaian Upah

6. Kesehatan Tenaga Kerja

7. Komposisi Kelompok Kerja

8. Kondisi Lapangan

9. Hubungan antar Tenaga Kerja

\section{HASIL DAN PEMBAHASAN}

Penelitian produktivitas pekerjaan pasangan dinding menggunakan batako dilakukan selama 14 hari. Studi kasus penelitian ini dilakukan pada perumahan dengan tipe 36 . Pasangan dinding tersebut dikerjakan oleh tenaga kerja secara berkelompok sebanyak lima kelompok kerja yang terdiri dari 6 orang tenaga kerja yaitu 2 orang tukang batu dan 4 orang pelayan dalam setiap kelompoknya. Dalam penelitian ini solidaritas tenaga kerja sangat berpengaruh, yaitu untuk mengetahui persentase produktivitas tenaga kerja dan total waktu yang dihasilkan oleh tenaga kerja nya. Untuk mendapatkan produktivitas diteliti 5 kelompok kerja yang masing-masing bekerja pada setiap rumah yang tipe nya sama.

Lokasi pekerjaan pasangan dinding dibagi menjadi 4 segmen bangunan karena disetiap segmen jumlah tukang berbeda-beda dikarenakan tukang bekerja borongan sehingga tukang mengerjakan semua bagian rumah. Berikut ini pembagian segmen pekerjaan pasangan dinding. Gambaran sketsa pembagian segmen rumah dapat dilihat pada Gambar 2. 
Vera Victya
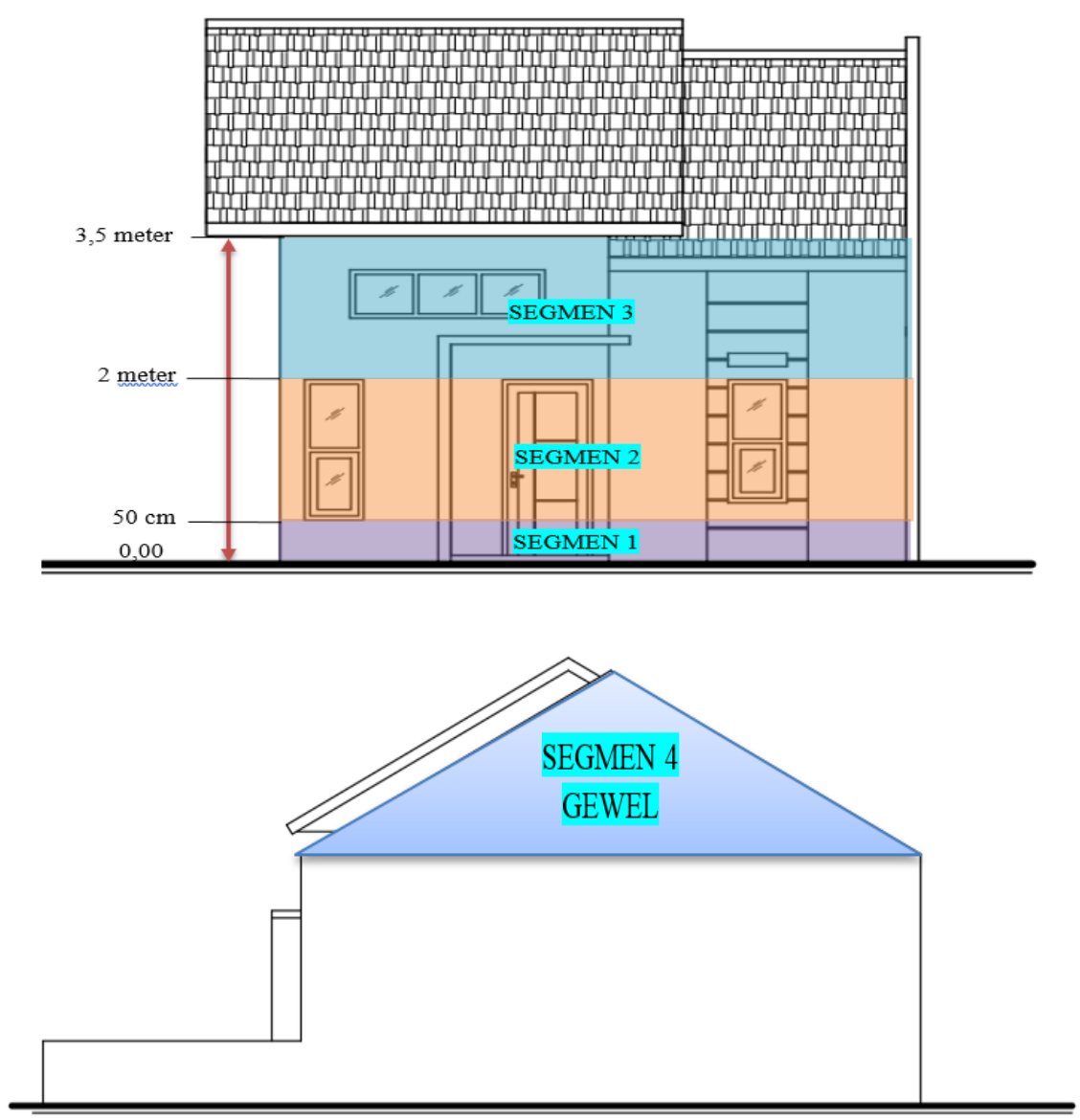

Gambar 2. Sketsa Pembagian Segmen Rumah

\section{Keterangan :}

Segmen 1 : Ketinggian pasangan batako $0 \mathrm{~cm}-50 \mathrm{~cm}$

Segmen 2 : Ketinggian pasangan batako $50 \mathrm{~cm}-2$ meter

Segmen 3 : Ketinggian pasangan batako 2 meter $-3,5$ meter

Segmen $4:$ Ketinggian pasangan batako 3,5 meter -6 meter

Tabel 1 menunjukkan hasil produktivitas kelompok kerja

Tabel 1. Hasil Produktivitas Kelompok Kerja

\begin{tabular}{ccccc}
\hline Kelompok Kerja & Segmen 1 & Segmen 2 & Segmen 3 & Segmen 4 \\
\hline Kelompok Kerja 1 & $1,48 \mathrm{~m}^{2} /$ jam & $2,46 \mathrm{~m}^{2} /$ jam & $2,10 \mathrm{~m}^{2} /$ jam & $1,98 \mathrm{~m}^{2} /$ jam \\
Kelompok Kerja 2 & $1,63 \mathrm{~m}^{2} /$ jam & $2,38 \mathrm{~m}^{2} /$ jam & $2,21 \mathrm{~m}^{2} /$ jam & $1,86 \mathrm{~m}^{2} /$ jam \\
Kelompok Kerja 3 & $1,43 \mathrm{~m}^{2} /$ jam & $2,41 \mathrm{~m}^{2} /$ jam & $1,98 \mathrm{~m}^{2} /$ jam & $1,92 \mathrm{~m}^{2} /$ jam \\
Kelompok Kerja 4 & $1,37 \mathrm{~m}^{2} /$ jam & $2,02 \mathrm{~m}^{2} /$ jam & $1,96 \mathrm{~m}^{2} /$ jam & $1,39 \mathrm{~m}^{2} /$ jam \\
Kelompok Kerja 5 & $1,18 \mathrm{~m}^{2} /$ jam & $1,73 \mathrm{~m}^{2} /$ jam & $1,48 \mathrm{~m}^{2} /$ jam & $1,34 \mathrm{~m}^{2} /$ jam \\
RERATA & $1,42 \mathrm{~m}^{2} /$ jam & $2,20 \mathrm{~m}^{2} /$ jam & $1,95 \mathrm{~m}^{2} /$ jam & $1,70 \mathrm{~m}^{2} /$ jam \\
\hline
\end{tabular}

Kelompok kerja 1 dan 2 rata-rata menghasilkan produktivitas lebih besar dari pada kelompok kerja yang lain dikarenakan letak gudang material paling dekat dengan pembangunan rumah sedangkan kelompok kerja 4 dan 5 menghasilkan produktivitas paling rendah dikarenakan letak gudang material 
berjarak paling jauh dari

lokasi pembangunan rumah. Sehingga letak material sangat berpengaruh terhadap produktivitas pekerjaan pada pekerjaan pasangan dinding.

Untuk mengetahui seberapa besar pengaruh usia, keahlian tenaga kerja, pengalaman tenga kerja, tingkat pendidikan, kecocokan terhadap upah, kesehatan tenaga kerja, kondisi lapangan, hubungan antar tenaga kerja, serta tim kelompok kerja terhadap tingkat produktifitas tenaga kerja yang didapatkan dari penyebaran kuisioner. Untuk mendapatkan hasil yang akurat maka dilakukan juga wawancara kepada tenaga kerja yang mengisi kuisioner serta kepada para pimpinan proyek. Penelitian dilakukan pada proyek pembangunan Perumahan Tapis Indah Regency Di Wilayah Kabupaten Paser, Kalimantan Timur.

Kuisioner ditujukan kepada 30 responden untuk menentukan kinerja tenaga kerja kontraktor khusus nya kepada para tukang batu yang bekerja pada pekerjaan pasangan batako yang terdiri dari 9 pertanyaan yang mewakili tentang produktivitas tenaga kerja. Nilai skor jawaban responden dalam penelitian ini mengacu pada skala 5 poin dari Likert, Urutan penilaian nya adalah sebagai berikut :

$1=$ Tidak Berpengaruh

$2=$ Kurang Berpengaruh

$3=$ Cukup Berpengaruh

$4=$ Berpengaruh

$5=$ Sangat Berpengaruh

Selanjutnya jawaban hasil kuisioner yang telah di isi oleh responden kemudian dianalisis untuk mengetahui hasil dari pengaruh variabel yang telah ditentukan serta menyajikan informasi tentang seberapa banyak responden menjawab 1, 2, 3, 4 dan 5 dalam menjawab sejumlah pertanyaan yang telah di ajukan. Dimana 1 adalah Tidak Berpengaruh, 2 adalah Kurang Berpengaruh, 3 adalah Cukup Berpengaruh, 4 adalah Berpengaruh dan 5 adalah Sangat Berpengaruh. Tabel 2 menunjukkan hasil analisis jawaban responden.

Tabel 2. Rekapitulasi Jawaban Hasil Responden

\begin{tabular}{|c|c|c|c|c|c|c|}
\hline \multirow{2}{*}{ PERTANYAAN } & \multicolumn{5}{|c|}{ JAWABAN RESPONDEN } & \multirow{2}{*}{ JUMLAH } \\
\hline & 1 & 2 & 3 & 4 & 5 & \\
\hline Umur Mempengaruhi Produktivitas & - & 4 & 6 & 11 & 9 & 30 \\
\hline $\begin{array}{l}\text { Pengalaman Kerja Mempengaruhi } \\
\text { Produktivitas }\end{array}$ & - & - & 2 & 3 & 25 & 30 \\
\hline $\begin{array}{l}\text { Keahlian Tenaga Kerja Mempengaruhi } \\
\text { Produktivitas }\end{array}$ & - & - & - & - & 30 & 30 \\
\hline $\begin{array}{l}\text { Tingkat Pendidikan Mempengaruhi } \\
\text { Produktivitas }\end{array}$ & - & 7 & 10 & 8 & 5 & 30 \\
\hline $\begin{array}{l}\text { Kesesuaian Upah Mempengaruhi } \\
\text { Produktivitas }\end{array}$ & - & - & 5 & 7 & 18 & 30 \\
\hline $\begin{array}{l}\text { Kesehatan Pekerja Mempengaruhi } \\
\text { Produktivitas }\end{array}$ & - & - & 8 & 5 & 17 & 30 \\
\hline $\begin{array}{l}\text { Kondisi Lapangan / Cuaca Mempengaruhi } \\
\text { Produktivitas }\end{array}$ & - & - & - & - & 30 & 30 \\
\hline $\begin{array}{l}\text { Tim Kelompok Kerja Mempengaruhi } \\
\text { Produktivitas }\end{array}$ & - & - & 5 & 11 & 14 & 30 \\
\hline $\begin{array}{l}\text { Hubungan Antar Pekerja Mempengaruhi } \\
\text { Produktivitas }\end{array}$ & - & 5 & 10 & 8 & 7 & 30 \\
\hline
\end{tabular}

Banyak faktor yang mempengaruhi tingkat produktivitas tenaga kerja yaitu faktor usia, pengalaman kerja/masa kerja, Keahlian tenaga kerja, tingkat pendidikan, kesesuaian upah, kesehatan pekerja, kondisi lapangan/cuaca, komposisi kelompok kerja dan hubungan antar pekerja. Semua variabel itu mempunyai pengaruh besar terhadap 
tingkat produktivitas tenaga kerja pada pekerjaan pasangan batako. Menurut data kuisioner yang dibagikan kepada 30 responden faktor yang sangat dominan terhadap tingkat produktivitas tenaga kerja adalah faktor Pengalaman kerja, keahlian tenaga kerja serta faktor kondisi lapangan/cuaca. Keahlian tenaga kerja dipengaruhi dari pengalamannya, semakin lama seseorang bekerja maka semakin meningkat pula keahliannya dalam bekerja. Maka daripada itu untuk bisa menjadi ahli perlu ada nya pengalaman yang banyak. Faktor pendidikan kurang berpengaruh pada pekerjaan pasangan dinding ini karena pekerjaan ini memerlukan keterampilan serta pelatihan tidak banyak memerlukan pemikiran. Serta faktor kondisi lapangan/cuaca juga sangat mempengaruhi produktivitas karena pekerjaan pemasangan dinding dilakukan di tempat terbuka.

\section{KESIMPULAN}

Produktivitas tenaga kerja dari suatu pekerjaan adalah sangat penting, pada dunia konstruksi tinggi rendahnya produktivitas kerja para tenaga kerja sangat mempengaruhi waktu pelaksanaan proyek konstruksi tersebut. Berdasarkan hasil analisis dan pengolahan data yang bisa diambil pada penulisan tesis ini adalah:

1. Besarnya produktivitas pekerjaan pasangan dinding batako dari ketinggian 0 lantai sampai $50 \mathrm{~cm}$ sebesar $1,42 \mathrm{~m}^{2} / \mathrm{jam}$, pada ketinggian $50 \mathrm{~cm}$ sampai 2 meter sebesar 2,20 $\mathrm{m}^{2} / \mathrm{jam}$, pada ketinggian 2 meter sampai 3,5 meter sebesar 1,95 $\mathrm{m}^{2} / \mathrm{jam}$, dan pada ketinggian 3,5 meter sampai 6 meter sebesar $1,70 \mathrm{~m}^{2} / \mathrm{jam}$.

2. Faktor yang berpengaruh dominan terhadap tingkat produktivitas pekerjaan pada pasangan dinding yaitu faktor keahlian tenaga kerja, faktor pengalaman serta faktor kondisi lapangan/cuaca.

3. Upaya yang harus dilakukan dalam peningkatan produktivitas tenaga kerja kontraktor pada proyek Pembangunan Perumahan Tapis Indah Regency Di Wilayah Kabupaten Paser, Kalimantan Timur adalah dengan lebih memperketat pengawasan terhadap tenaga kerja nya
4. sehingga dapat bekerja secara maksimal serta perlu nya pelatihan tenaga kerja untuk mendapatkan sertifikat keahlian sehingga yang dipilih oleh kontraktor adalah pekerja yang sudah memiliki seritifikat keahlian agar pada saat pekerja terjun ke lapangan sesuai dengan apa yang kita inginkan.

\section{DAFTAR RUJUKAN}

Aft, Lawrence S. 1983, Productivity Measurement And Improvement, New Jersey, USA, Prentice Hall.

Badan Pusat Statistik. 2017. Indikator Kesejahteraan Rakyat Kabupaten Paser. Kabupaten Paser : Badan Pusat Statistik Kabupaten Paser.

Darmono. 2006. Manajemen Perpustakaan. Jakarta : Grasindo.

Dinas Tenaga Kerja Dan Transmigrasi Provinsi Kalimantan Timur. 2013. Rencana Tenaga Kerja Provinsi Kalimantan Timur Tahun 2014-2018. Jakarta. Pusat Perencanaan Tenaga Kerja-Kemnakertrans RI.

Dipohusodo, Istimawan. 1996. Manajemen Proyek \& Kontruksi. Yogyakarta : Badan Penerbit Kanisius.

Ervianto, W. 2005. Manajemen Proyek Konstruksi. Yogyakarta : Andi.

Handoko, Hani T. 1984. Dasar-Dasar Menajemen Produksi dan Operasi. Yogyakarta : BPFE.

J. Ravianto. 1985. Produktivitas dan Manajemen. Yogyakarta : UGM press

Kaming, P. F., Riano, A. G., 1997, Faktor Penentu Kinerja Efektif Bagi Konsultan Manajemen Proyek, Konferensi Nasional Teknik Sipil 7. Surakarta : Universitas Negeri Sebelas Maret

Lim, Ewe Chye, Price, A.D.F. 1995. Construction Productivity Measurements For Residential Building in Singapore, Proceedings: First International Conference on Construction Project Management, Singapore, 
Nawawi, Hadari. 2008. Manajemen Sumber Daya Manusia Untuk Bisnis Yang Kompetitif. Yogyakarta : Gadjah Mada Univesity Press.

Nazir, Moh. 1983. Metode Penelitian. Jakarta : Ghalia Indonesia.

Oglesby. Dkk. 1989. Productivity Improvement In Construction. McGraw-Hill Book Company. New York

Olomolaiye dkk. 1998. Contruction Productivity Managemen. Harlow. Essex

Pilcher, R. 1992, Principle of Construction Management $3^{\text {ed }}$ Edition, Toronto Inc Mc. Graw Hill Book Company. New York

Soekirno, Purnomo. 1999. Pengantar Manajemen Proyek, Diktat Kuliah Magister Teknik Sipil UII, Yogyakarta

Soekirno, Purnomo. 2000. Metode Konstruksi I, Bangunan, Sistem Struktur, Teknologi dan Metode Konstruksi, Diktat Kuliah Magister Teknik Sipil UII, Yogyakarta
Siagian, Sondang P. 2002. Kiat meningkatkan produktivitas kerja. Jakarta : Rineka Cipta

Sinungan, Muchdarsyah. 2003. Produktivitas Apa Dan Bagaimana. Jakarta : Bumi Aksara.

Soeharto, Iman. 1995. Manajemen Proyek : Dari Konseptual Sampai Operasional. Jilid 1. Jakarta : Erlangga.

Sugiyono. 2002. Statistika untuk Penelitian. Bandung: Alfabeta.

Sutemeister.R.A. 1976. People and Productivity (Third Edition) Mc. Grow. Hill. Book Company. New York.

Walpole, Ronald E. 1995. Pengantar Statistik. Edisi ke-3. Jakarta : PT. Gramedia Pustaka Utama

Wignjosoebroto, Sritomo. 1995, Ergonomi, Studi Gerak dan Waktu, edisi Pertama, Jakarta : Guna Widya 